\section{THU0326 DISCONTINUATION AND SWITCHING PATTERNS OF TUMOUR NECROSIS FACTOR INHIBITOR (TNFI) THERAPY IN TNFI-NAIVE AND TNFI-EXPERIENCED PATIENTS WITH PSORIATIC ARTHRITIS IN THE US CORRONA PSORIATIC ARTHRITIS/ SPONDYLOARTHRITIS (PSA/SPA) REGISTRY}

${ }^{1}$ P. Mease, M. Liu', B. Gershenson ${ }^{3}$, P. Hur ${ }^{4}$, J. Greenberg ${ }^{5} .{ }^{1}$ Swedish Medical Center and University of Washington, Seattle; ${ }^{2}$ Corrona, LLC, Waltham; ${ }^{3}$ University of Massachusetts Medical School, Worcester, ${ }^{4}$ Novartis Pharmaceuticals Corporation, East Hanover, ${ }^{5}$ New York University School of Medicine, New York, USA

Background: To better inform treatment decisions for patients with psoriatic arthritis (PsA), it is important to understand outcomes in patients who initiate a first line vs a subsequent line of TNFi therapy. Limited studies have evaluated persistence and switching of TNFi therapy in TNFi-naive vs TNFi-experienced US patients with PsA.

Objectives: To examine discontinuation and switching of TNFis in TNFi-naive and -experienced patients with PsA in the US Corrona PsA/SpA Registry.

Methods: All patients aged $\geq 18$ years in the Corrona PsA/SpA Registry who were diagnosed with PsA, initiated a TNFi (index therapy) between March 2013 and , January 2017 and had $>1$ follow-up visit after TNFi initiation were included. Patients were stratified by prior TNFi use (TNFi naive: no prior TNFi or other biologic; TNFi experienced: $\geq 1$ prior TNFi). Patient demographics and clinical and disease characteristics were assessed at the time of TNFi initiation (baseline). Time to discontinuation of the index TNFi (with or without switching) and time to switch to another biologic were assessed by Kaplan-Meier analysis. Log-rank tests were used to assess differences in persistence and switching between the TNFi-naive and -experienced cohorts. Provider-reported reasons for discontinuation of the index TNFi were summarised descriptively.

Results: 318 patients with PsA were included (TNFi naive, $n=171$; TNFi experienced, $n=147$ ), with a total follow-up of 579.2 person-years. Experienced patients had a longer mean (SD) disease duration (13.3 [10.0] vs 9.5 [9.7] years; $p<0.01)$ and a higher proportion had a history of prednisone use ( $27.9 \%$ vs $17.5 \%$; $p=0.03)$ compared with naive patients. A total of 75 naive $(43.9 \%)$ and 80 experienced patients $(54.4 \%)$ discontinued their index TNFi, including $33(19.3 \%)$ and 48 (32.7\%), respectively, who switched to a new biologic. The median $(95 \% \mathrm{Cl}$ ) time to discontinuation of the index TNFi in naive vs experienced patients was 27 (22 to 33 ) vs 20 (18 to 28 ) months, respectively (figure 1). Among those who discontinued their TNFi, the mean (SD) time to discontinuation was 14.5 (8.0) months in naive patients vs 14.0 (8.9) months in experienced patients. Due to the low number of switching events, the median time to switch of the index TNFi could not be estimated. Among those who switched to a new biologic, the mean (SD) time to switch was 16.0 (8.1) vs 13.5 (7.5) months in naive and experienced patients, respectively. TNFi-naive patients had greater persistence with their index TNFi $(p=0.03)$ and were less likely to switch to another biologic $(p=0.002)$ compared with TNFi-experienced patients. Provider-reported reasons for discontinuation included lack of effect (naive, $71 \%$; experienced, $62 \%$ ), side effects (10\%; $23 \%$ ), social reasons $(6 \% ; 3 \%)$, doing well $(3 \% ; 0 \%)$, and other $(10 \% ; 12 \%)$.

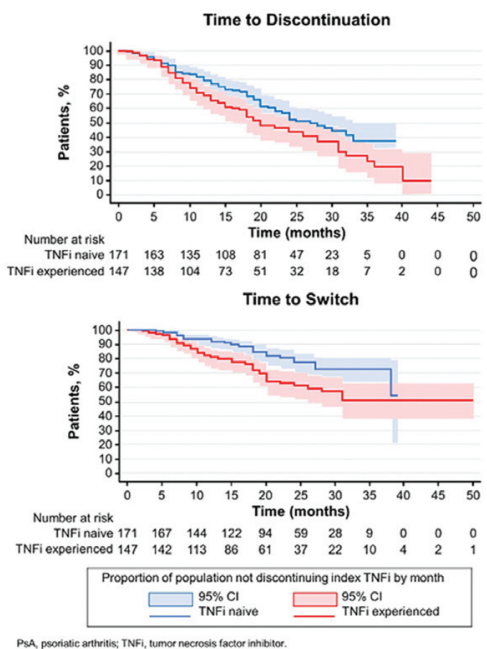

Abstract THU0326 - Figure 1. Time to Discontinuation (With or Without Switching) and Time to Switch of Index TNFi in TNFi-Naive and TNFi-Experienced Patients With PsA. PsA, psoriatic arthritis; TNFi, tumour necrosis factor inhibitor.
Conclusions: In this real-world analysis of US patients with PsA, TNFi-experienced patients were more likely to discontinue and switch their index TNFi and had a shorter time to discontinuation compared with TNFi-naive patients. These results may help inform treatment decisions when selecting later lines of TNFi therapy in patients with PsA.

Acknowledgements: This study was sponsored by Corrona, LLC.

Disclosure of Interest: P. Mease Grant/research support from: AbbVie, Amgen, BMS, Celgene, Lilly, Novartis, Pfizer, UCB, Consultant for: AbbVie, Amgen, BMS Celgene, Corrona, Genentech, Janssen, Lilly, Merck, Novartis, Pfizer, UCB, Speakers bureau: AbbVie, Amgen, BMS, Celgene, Genentech, Janssen, Pfizer UCB, M. Liu Employee of: Corrona, LLC, B. Gershenson Employee of: University of Massachusetts Medical School, P. Hur Employee of: Novartis, J. Greenberg Shareholder of: Corrona, LLC, Consultant for: Eli Lilly, Genentech, Janssen, Novartis, Pfizer, Employee of: Corrona, LLC DOI: 10.1136/annrheumdis-2018-eular.149

\section{THU0327 REAL WORLD (RW) EXPERIENCE WITH AN ANTI-IL-17A INHIBITOR IN BIOLOGIC NAÏVE AND BIOLOGIC EXPERIENCED PSORIATIC ARTHRITIS (PSA) PATIENTS}

${ }^{1}$ R. Moon, J. Hill ${ }^{2}$, N. Booth ${ }^{1}$, S. Lobosco'. ${ }^{1}$ Adelphi Real World, Maccelsfield, UK; ${ }^{2}$ Eli Lilly and Company, Indianapolis, USA

Background: Two IL-17A inhibitors are approved for the treatment of PsA, ixekizumab and secukinumab. At the time of this survey, real world evidence was only available for secukinumab, which was approved for PsA in 2016 in EU, Australia and Switzerland. Secukinumab label dose for PsA patients with either concomitant moderate to severe plaque psoriasis or anti-TNF $\alpha$ inadequate responders is $300 \mathrm{mg}$. For other patients, the recommended dose is $150 \mathrm{mg}$. All patients receive a loading dose regimen by S.C. injection at Weeks $0,1,2,3$ and 4 , followed by monthly maintenance dose. Little data are published on the RW utilisation of secukinumab in PsA.

Objectives: Describe RW dose utilisation of an anti-IL-17A inhibitor, among biologic naïve and biologic experienced PsA patients.

Methods: Data from a chart review study conducted in 2017 across France, Ger many, Italy, Spain, UK, Australia and Switzerland where secukinumab is reimbursed were used. Specialists were recruited by field-based interviewers, and provided information on demographics, Body Surface Area (BSA), time since diagnosis and treatment for their adult PsA patients currently receiving secukinumab.

Results: 212 rheumatologists, 89 dermatologists, 1 orthopedist provided data for 1451 patients. Mean age 50.6 years, $47 \%$ female, mean time since PsA diagnosis 5.9 years and $86 \%$ had concomitant psoriasis. $96 \%$ received prior csDMARD(s) and $8 \%$ prior apremilast. 29\% (425) were biologic naïve and $71 \%(1024)$ biologic experienced (limited differences between specialists: 74\% rheumatologists; $63 \%$ dermatologists). $34 \%, 24 \%$, and $13 \%$ received, 1, 2, and $3+$ prior biologics respectively.

Among biologic naïve patients on $150 \mathrm{mg}, 36 \%(52 / 145)$ had a BSA $\geq 10 \%$, where the recommended dose is $300 \mathrm{mg}$ at secukinumab initiation. $29 \%(274 / 930)$ of biologic experienced patients received secukinumab at $150 \mathrm{mg}$, not the recommended $300 \mathrm{mg}$ dose (figure 1)
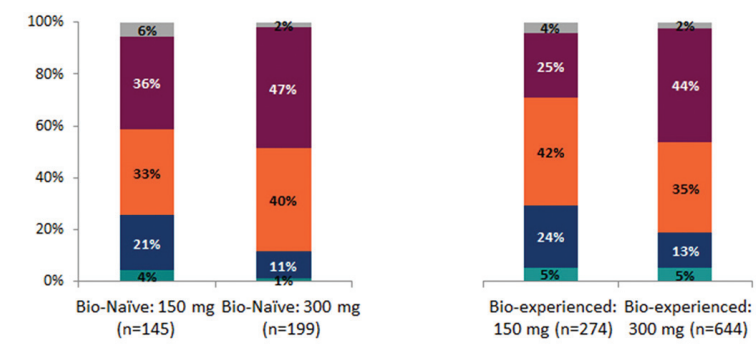

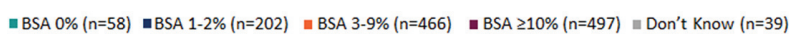

Abstract THU0327 - Figure 1. Secukinumab Dosing: Current Dose (Loading or Maintenance). *For this analysis, moderate to severe psoriasis was defined as BSA $\geq 10$

Conclusions: In the RW, secukinumab is prescribed mainly in biologic experienced patients (71\%) and is not universally prescribed at the recommended dose for PsA. Specifically, of those who are biologic naïve (29\%), 36\% of patients on $150 \mathrm{mg}$ had moderate to severe psoriasis, which is outside the recommended dose. Further RW experience is needed for ixekizumab.

Acknowledgements: Acknowledgements: This chart review study was designed and run by Adelphi Real World. The study was supported by a number of 